\title{
The Importance of the Physical Environment for Child and Adolescent Mental Health Services
}

\section{S L Rogers, S J Edwards, P Hudman and R Perera}

\begin{abstract}
Objective: This study examined the relationships between appraisals of the physical environment with the subjective experience of consumers, and work satisfaction of clinicians, in Child and Adolescent Mental Health Services (CAMHS).
\end{abstract}

Design, setting, and outcome measures: A survey of clinicians, parent/guardians, and child/adolescents was conducted across eight community CAMHS in Western Australia. Respondents evaluated the waiting room and therapy rooms on a number of environmental attributes, and factor analysis was carried out to confirm that these ratings loaded on an overall appraisal of the physical environment measure. This measure was then correlated with self-reported subjective experience of consumers, and overall work satisfaction of staff members.

Results: Clinicians were found to be much more critical of the physical environment compared with consumers. Moderate associations were found between appraisal of the physical environment and subjective experience of consumers. A strong positive association was found between clinician appraisal of the physical environment and overall work satisfaction.

Conclusions: The present study adds to the limited existing research arguing for the important role that the physical environment can have upon both consumer and staff experience in mental health settings. The present study provides empirical evidence to justify steps being taken to enhance the physical environment in mental health clinics. The inter-relationship between physical environment attributes suggests there is potential for managers to improve the overall perception of clinic space via relatively small actions (e.g., adding a nice piece of artwork).

Abbreviations: CAMHS - Child and Adolescent Mental Health Services.

Key words: mental health; physical environment; consumer satisfaction; job satisfaction; child and adolescent mental health; health services.

\section{Shane L Rogers}

Psychology and Social Science

Edith Cowan University

Perth, Western Australia, Australia.

\section{Stephen J Edwards}

Child and Adolescent Mental Health Services

Western Australia Health Department

Perth, Western Australia, Australia.

\section{Paul Hudman}

Child and Adolescent Mental Health Services

Western Australia Health Department

Perth, Western Australia, Australia.

\section{Rebecca Perera}

Psychology and Social Science

Edith Cowan University

Perth, Western Australia, Australia.

Correspondence:

shane.rogers@ecu.edu.au

\section{Introduction}

A broad research literature exists investigating how the therapeutic alliance between a therapist and client is influenced by therapist techniques, and also the personal characteristics of therapists and clients. [1] However the impact the physical environment has upon therapeutic process and outcome lacks the same level of understanding. [2-4] The physical environment has been shown to have an impact upon health and well-being in office workplaces, [5] and hospital workplaces. [6,7] However a recent review of the literature revealed that research investigating the impact of the physical environment in mental health services is lacking, and especially for community mental health services. [8] Research investigating the impact of the physical environment has the potential to uncover ways that mental health services can improve service quality. This can in turn facilitate the speed of treatment, 
and reduce associated costs. The present study examines the relationship between perceptions of the physical environment in child and adolescent mental health services (CAMHS), with self-reported client emotional experience, and clinician work satisfaction.

\section{Physical environment in the clinic - the waiting room, and therapy rooms}

The waiting room is a very important space for a health clinic. On the first visit to the facility clients typically must walk through the waiting room to approach the administration staff, and then spend some time waiting before being seen by a health practitioner. Therefore the waiting room space has an important influence upon the formation of a first impression of the facility. $[9,10]$ In the context of mental health, this is an especially important issue. An initial negative first impression can place the therapy process on the back foot before it has started by reflecting poorly upon the therapist, and therefore unnecessarily increase the difficulty of establishing therapeutic rapport. [11,12]

Research also highlights the importance of the physical environment during counselling sessions in the therapy space. [2] A classic study by Chaikin, Derlega, and Miller (1976) found that in a simulated therapy session university students were more likely to engage in more self-disclosure in a room made to be perceived as soft (comfortable seating, softer lighting via lamps, rug on the floor, framed pictures on walls, and various other accessories) versus hard (brown asphalt tile floor, plain walls, overhead fluorescent lighting, and uncomfortable seating). In a similar study, Miwa and Hanyu (2006) found that dim lighting produced more favourable reported feelings of relaxation and impressions of the interviewer, and more self-disclosure, compared to bright lighting. Backhaus (2008) examined preferences for different environmental aspects of therapy rooms and found that soft and natural lighting was preferred over bright lighting. Additionally, both therapists and clients reported that a sense of privacy, minimal transmission of sound, comfortable furnishings, artwork, plants, magazines/ books, a clock, and personal memorabilia were all preferable aspects for a therapy room. Devlin and colleagues conducted a series of studies that gave American university students, [13] university students from Turkey and Vietnam [14] and American therapists [15] a set of 30 photographs of different therapy rooms. They reported that across all samples the evaluations (comfort, quality of care, and impressions of therapist) were more positive for softer, and more orderly rooms. Unfortunately no prior research has focused upon a child/adolescent mental health setting.
In the Australian context, the importance of the physical environment has been implicitly recognised by the growing headspace (www.headspace.org.au/) initiative of the National Youth Mental Health Foundation. $[16,17]$ This initiative provides an alternative mental health service for 12-25 year olds. One of the primary aims of this initiative is to increase youth participation with mental health services by providing a more 'youth friendly' service. [16] The service website states that 'Centres are built and designed with input from young people so they don't have the same look or feel as other clinical services.' (see: www.headspace.org. au/about-us/). The service has enjoyed rapidly increasing popularity since inception in 2007 , and is projected to reach 100 centres by 2016. [17] The speed of growth has meant evaluation research has not kept pace with the expansion of the service, [18] although see recent evaluative work by Simmons et al [19] and Rickwood et al. [20] The present study provides an assessment of an implicit assumption that has guided the implementation of the headspace initiative: that an association will exist between client appraisal of the physical environment and client emotional experience within that environment.

\section{The relationship between the physical environment and clinician job satisfaction}

There is a large research corpus finding a relationship between work satisfaction and the appraisal of the physical work environment across a wide range of office settings, $[21,22]$ and that the physical office setting can have implications for the mental and physical health of employees. $[5,23]$ However the relationship between appraisal of the physical environment and overall work satisfaction has not been examined in the context of child mental health services. Even for mental health services in general, the physical environment has been paid little attention by researchers. [3] One study conducted in the 1970s reported that when a sample of clinical staff relocated to a new and improved facility, their satisfaction with their physical environment improved with an associated improvement in their overall work satisfaction. [24] Research shows that mental health workers are at an elevated risk of burnout due to the demanding nature of working in constant contact with individuals experiencing emotional difficulties. [25,26] Therefore, investigating ways that clinician job stress may be alleviated is a valuable endeavour in order to improve service quality and reduce staff turnover. Investigating the influence of the physical environment upon clinician job satisfaction has potential to reveal cost-effective strategies for improvement. 


\section{The present study}

The present study seeks to add to the research literature by examining the relationship between appraisal of the physical environment and outcome measures such as client selfreported emotional experience and clinician self-reported general work satisfaction, in the context of child/adolescent mental health services. Some environmental factors can be considered to be indoor environmental attributes (comfort, safety, space, privacy, lighting and noise), and others considered interior design attributes (toys/books, artwork, and plants) as suggested by Rashid and Zimring. [7] Prior research has revealed that participant appraisal of different environmental attributes tends to be highly inter-related due to a halo effect. [27] For example, better lighting may contribute to an increased sense of space and comfort in the environment, whilst a poor piece of artwork may detract from how other environmental aspects are perceived, and so on. Therefore in the present study it was expected that ratings of the physical environment would be highly interrelated and could be combined into a single overall appraisal of the physical environment measure. Based on prior research that indicates the physical environment can have an influence on the experience of clients, it was expected that the client's overall appraisal of physical environment would be associated with the client's self-rated emotional experience. It was also expected that the clinician overall appraisal of the physical environment would be positively associated with their level of work satisfaction.

\section{Method - participants}

The sample consisted of 59 clinical staff employed by CAMHS (69\% female), 85 parents/guardians ( $87 \%$ female), and 79 children/adolescents (70\% female) surveyed across eight government-funded community clinics in the metropolitan area of Western Australia. For the child/adolescent group the distribution of age was: younger than 8 years (1\%), 9-12 years (24\%), $13-16$ years (62\%), and $17-20$ years (13\%). The length of experience with the clinic was: a few weeks (6\%), a couple of months (28\%), about six months (14\%), about a year $(25 \%)$, more than a year $(22 \%)$, and no response to this question (5\%). The length of experience with the clinic for the parents/guardians was: a few weeks (6\%), a couple of months (22\%), about six months (14\%), about a year (21\%), more than a year (32\%), and no response to this question (5\%). The length of experience working in the mental health industry for the clinician sample was: $2-5$ years (14\%), 6-10 years (15\%), and more than 10 years (71\%). Age information for the clinicians and parent/guardians was not recorded. This research received ethics approval from the West Australian Health Department, audit number - 588QP.

\section{Method - procedure}

For clients (parents/guardians and child/adolescents) surveys were left in the waiting room and could be returned to an anonymous survey box in the clinic waiting room. The data collection phase of the project lasted for approximately three months, therefore responses were obtained from clients that varied widely on their stage of treatment. Clients were asked to rate a number of physical environment attributes (safety, comfort, space, privacy, lighting, noise, toys/books, artwork, and plants) separately for both the waiting room and the therapy rooms on a scale: Very bad, Bad, OK, Good, Very Good. Clients were also asked to rate how often they typically felt four different emotions (afraid, uncomfortable, bored, calm) separately for both the waiting room and therapy rooms on a scale: Never, Sometimes, Often, Always. An open-ended text box was included at the end of the survey for clients to provide any comments they might have about the clinic environment. The survey instrument is provided in Figure 1 below. Note that smiley faces were used as part of the response scales in order to make the survey more colourful and engaging to foster participation.

Clinicians were surveyed by the first author of this paper attending staff meetings at clinics. Prior to attendance, service managers of the clinics were emailed to obtain their consent for attendance. Clinicians were asked to provide ratings of different attributes for the waiting room and therapy rooms in the same way as the clients, however smiley faces were not used on their survey version. Note that clinicians were asked to provide their own personal perception of the environment, not their estimate of client perceptions.

Additionally, clinicians were also asked to provide a response to the statement 'Working at CAMHS I feel satisfied with working conditions' on a scale: Not at all, Somewhat, Moderately, Very and Extremely. There were a number of other questions on the clinician survey that are beyond the scope of this present study and are not reported here.

Ratings for different environmental attributes were obtained from all participants with the aim of combining ratings into an overall appraisal score to be correlated with client emotional experience of the clinic, and clinician job satisfaction. Additionally, client and clinician perceptions could be contrasted. 
Figure 1: The survey used for child/adolescent and parent/guardian participants. Note that the age question was only able to distinguish between different ages for the child/adolescents.

\author{
CAMHS FACILITIES SURVEY \\ *Please answer this survey for the facility you are currently attending* \\ *Any questions about this survey please ask the office staff* \\ I am a... (put an $X$ through your choice) \\ $\square$ Child $\square$ Adolescent $\square$ Parent/Guardian \\ I am... (put an X through your choice) \\ $\square$ Female $\square$ Male \\ How old are you? (put an X through your choice) \\ $\square$ Younger than 8 years $\square$ 9-12 years old $\square$ 13-16 years old $\square$ 17-20 years old \\ $\square$ 21-30 years old $\square$ Older than 31 years
}

I have been coming to CAMHS for... (put an Xthrough your choice)

$\square$ A week or less A few weeks $\square$ A couple of months $\square$ About 6 months $\square$ About a year $\square$ More than a year

Please rate the waiting room and therapy rooms on the things listed below (put an X through your choice)

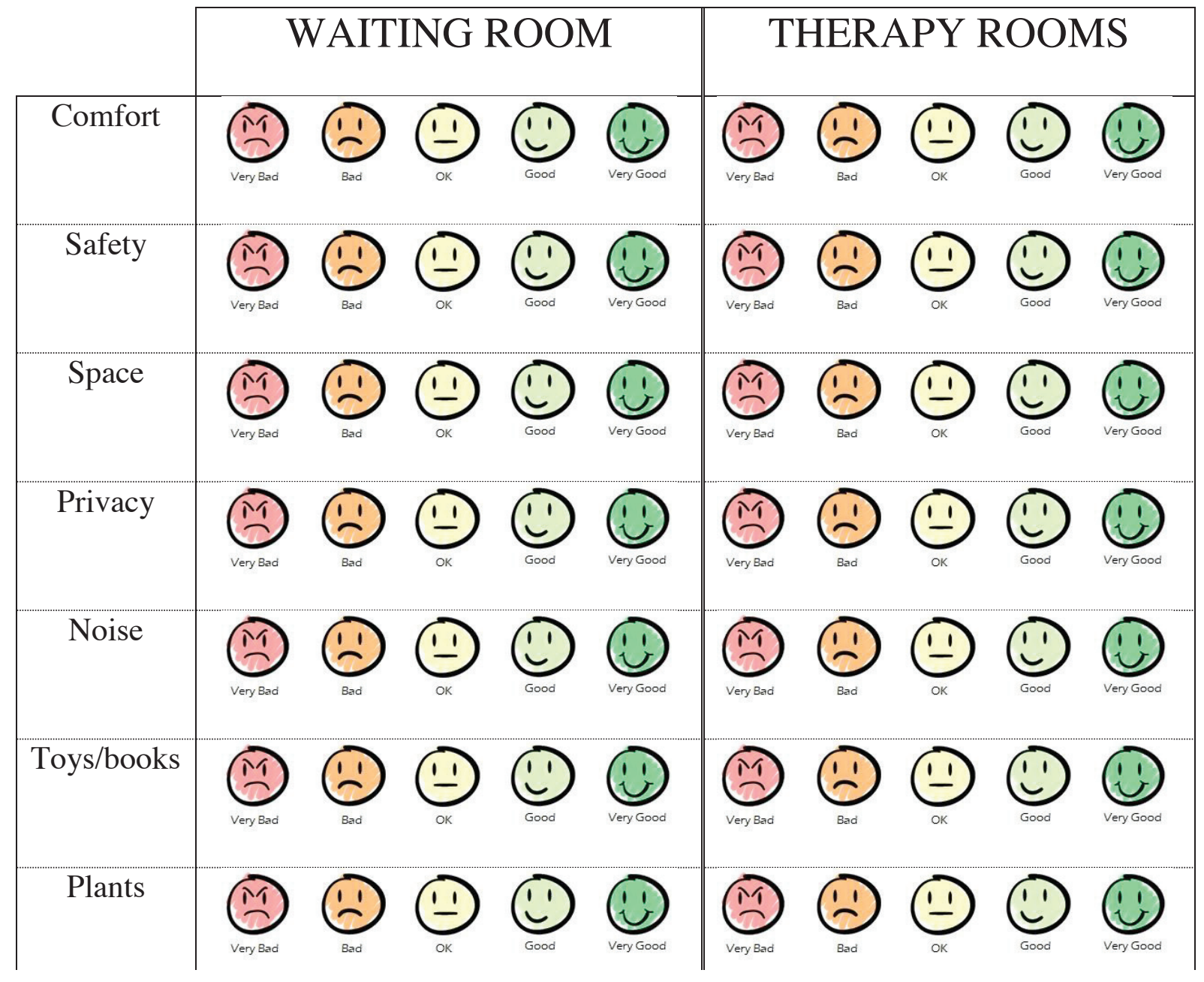


Figure 1: The survey used for child/adolescent and parent/guardian participants. Note that the age question was only able to distinguish between different ages for the child/adolescents continued

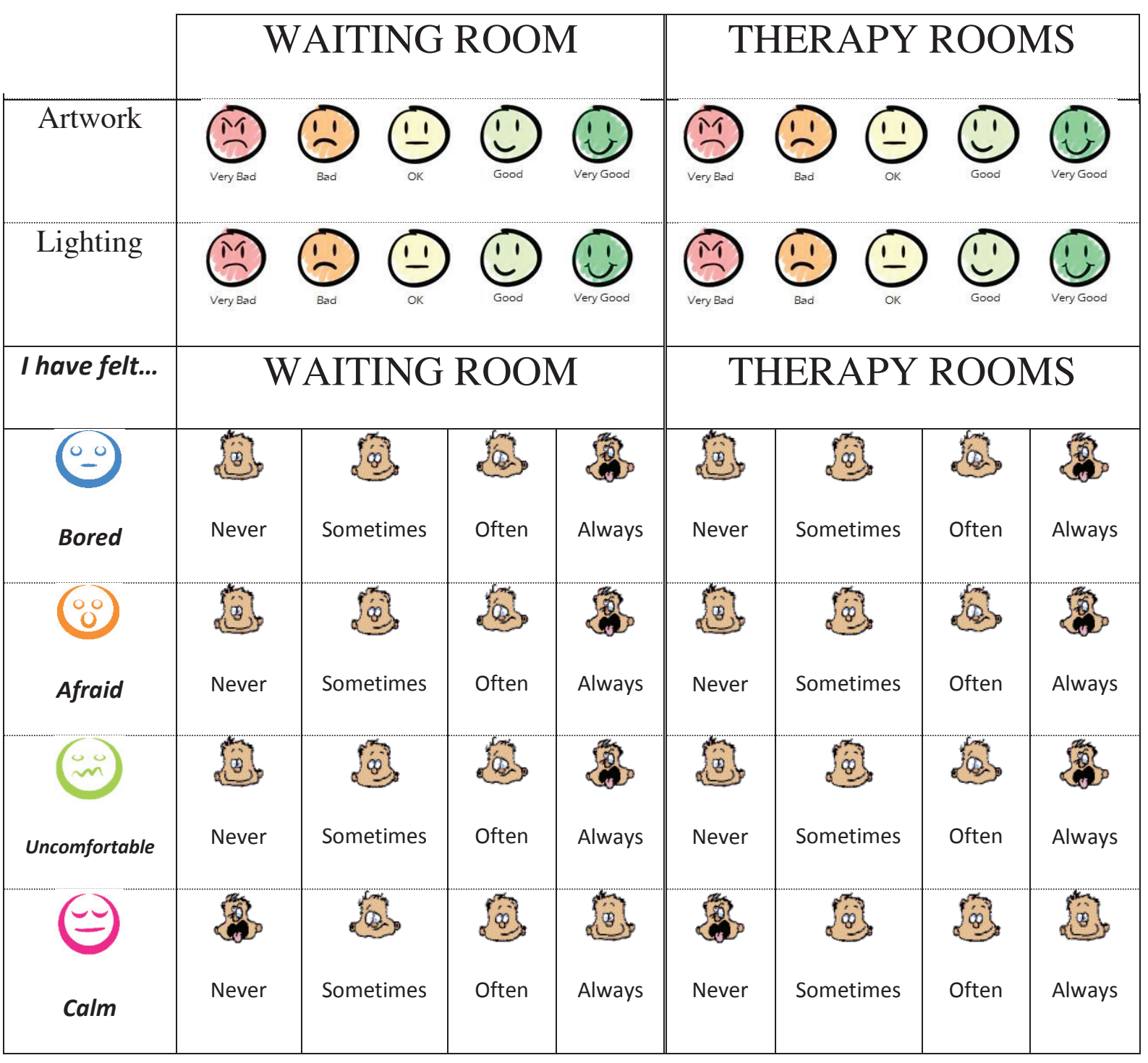

\section{Results}

The ratings for all environmental attributes for the waiting room, and therapy rooms, across each surveyed group are provided in Figure 2. Across all attributes, for both the waiting room and therapy rooms, the client respondents gave largely positive ratings. Comparatively, the clinicians were consistently less positive in their appraisals.

It was expected that positive inter-relationships would exist between appraisals of the different environmental attributes. Due to the existence of negative skew in the ratings of clients (see Figure 2), Spearman rank correlations were conducted. With nine environmental attributes rated, for both the waiting room and therapy rooms, across all groups, there were a total of 216 correlation values obtained.
For the sake of brevity, the patterns of inter-correlations are summarised in a single table (see Table 1) instead of reporting six large correlation tables. As reported in Table 1, the pattern of correlations was consistent with expectations that ratings among the different attributes would be consistently moderately positively associated.

An overall appraisal score across each of the surveyed groups, for both the waiting room and therapy rooms, was obtained via averaging across ratings for the different attributes. The mean overall appraisal scores are presented in Figure 3. The overall waiting room and therapy rooms appraisal score was strongly positively associated for the parents/guardians (Pearson $r=.91, p<.001$ ), child/adolescents (Pearson $r=$ $.74, p<.001$ ), and clinicians (Pearson $r=.67, p<.001$ ). A 3 
Figure 2: Participant ratings of the waiting room and therapy rooms for a number of different environmental attributes

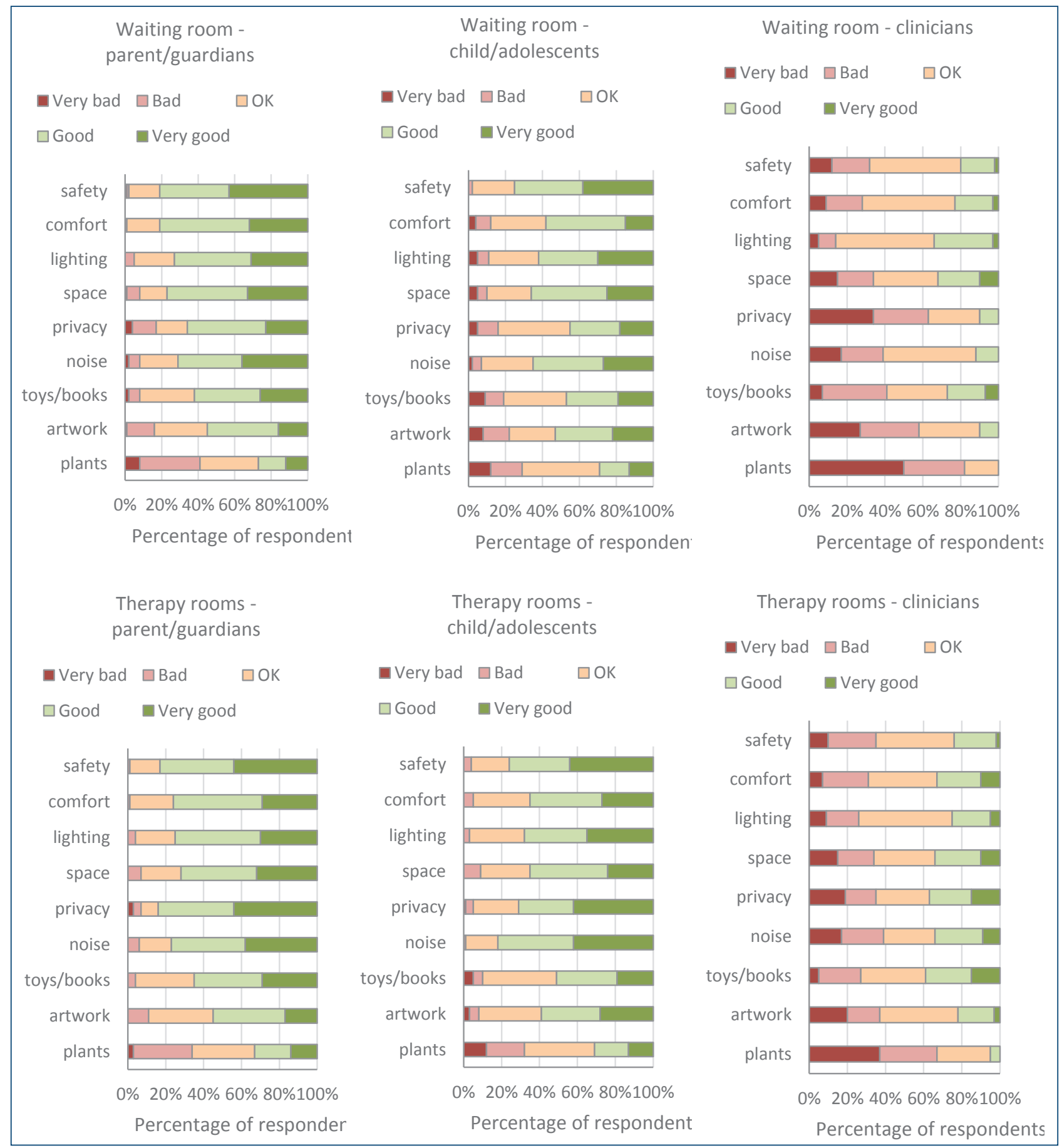

(group - child/adolescents, parent/guardians, clinicians) x 2 (space - waiting room, therapy rooms) mixed design ANOVA was conducted to examine differences among the mean overall appraisal scores. A significant main effect of group was obtained $(F(2,209)=48.88, \mathrm{p}<.001, \mathrm{np} 2=$ .32), with follow up comparisons revealing the clinicians were overall more negative in their appraisal of the clinic environment compared to both the child/adolescents and parent/guardians ( $p s<.05$ ). There was no significant difference found between child/adolescents and parent/ guardians $(p>.05)$. There was also a small significant main effect of space $(F(1,209)=35.11, p<.001, n p 2=.14)$, with no significant interaction between group and space $(F(2,209)=$ $.85, p=.43, n p 2=.01)$. As can be observed in Figure 3 the main effect of space was obtained due to a consistently more favourable appraisal of the therapy rooms compared to the waiting room space across the three groups of participants. However this effect is much smaller than the overall difference between clinicians compared with the other two groups. 
Table 1: Summary of the Spearman inter-correlations between ratings for the different factors - across the total 216 correlation values only two were statistically non-significant

\begin{tabular}{|l|c|c|}
\hline & $\begin{array}{c}\text { MEAN SPEARMAN CORRELATION } \\
\text { BETWEEN RATINGS OF FACTORS } \\
\text { (STANDARD DEVIATION) }\end{array}$ & \\
WAITING ROOM & & \\
Parent/guardians & $.56(.11)$ & $.33-.78$ \\
Child/adolescents & $.48(.11)$ & $.25-.65$ \\
Clinicians & $.69(.12)$ & $.14-.71$ \\
THERAPY ROOMS & & \\
Parent/guardians & $.69(.12)$ & $.43-85$ \\
Child/adolescents & $.46(.13)$ & $.19-.67$ \\
Clinicians & $.56(.13)$ & $.37-.92$ \\
\hline
\end{tabular}

Figure 3: The mean overall participant appraisal of the physical environment for the waiting room and therapy rooms. Bars represent $95 \%$ confidence limits

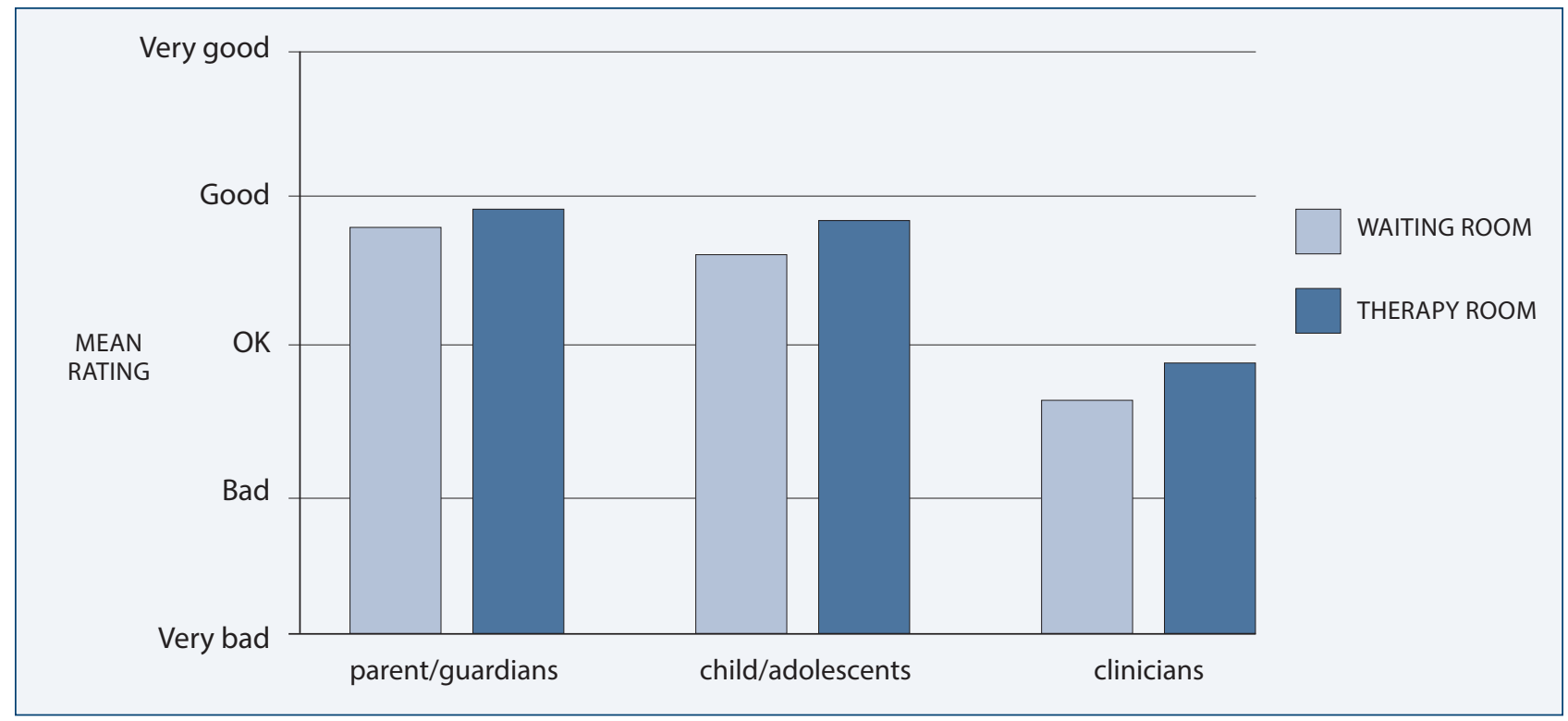

Exploring the self-reported client emotional experience in the waiting room and therapy rooms revealed encouraging results, see Figure 4. The parent/guardians and child/ adolescents typically reported feeling calm 'often' in both the waiting room and therapy rooms. The experience of negative emotions (i.e., afraid, uncomfortable, and bored) was generally rated 'sometimes' or less. An exception is the reported boredom of child/adolescents in the waiting room with around half of respondents stating 'often' or 'always'.

Of interest was the extent the overall appraisal of the physical environment might associate with client selfreported emotional experience in the clinic space. Due to the use of a 4-point scale and the highly skewed nature for some of the variables, Spearman rank correlations were carried out instead of Pearson correlations, (see Table 2). A moderate positive association was found between feeling calm in the clinic and appraisal of the physical environment. Moderate negative associations were found between feeling bored and uncomfortable and appraisal of the physical environment. Only small negative or non-significant associations were found between appraisals of the physical environment with self-reported fear. Overall, results were consistent with expectations that emotional experience when in the clinic would have a relationship with appraisal of the clinic physical environment. 
Figure 4: Ratings of different emotions experienced in the waiting room and therapy rooms by parent/guardian and child/adolescent respondents.

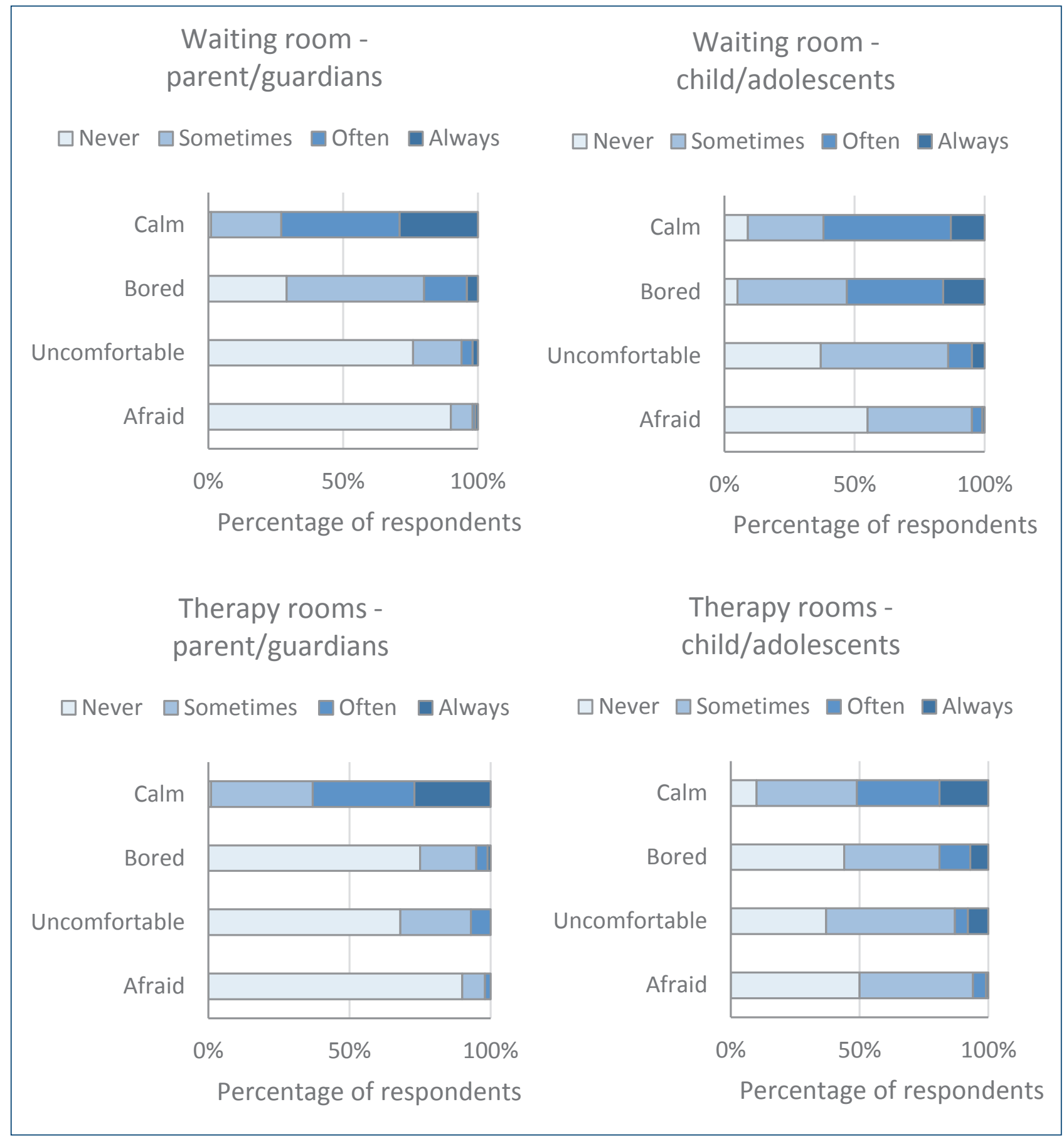

The client survey included an option to provide written feedback about the clinic's physical environment. There were 31 parent/guardians (36\%) and 16 child/adolescents (20\%) who provided a comment. Comments were fairly evenly split between two broad types: suggestions for improvement, for example: 'Tissues in waiting room please. Why do chairs in waiting room have to FACE other people?', and praise for the service, for example: 'My daughter's counsellor and the staff are amazing and very helpful in every situation'.
In the present study it was also expected that appraisal of the physical environment by clinicians would be associated with their self-reported overall work satisfaction. When asked the statement 'Working at CAMHS I feel satisfied with working conditions' clinician responses were: not at all (22\%), somewhat (36\%), moderately (25\%), Very (15\%), and extremely (2\%). Responses to this statement were positively correlated with both appraisal of the waiting room (Pearson $r=.60, p<.001$ ) and therapy rooms (Pearson $r=.57, p<$ 
Table 2: Spearman correlations between the self-reported level of emotion experienced in the clinic with overall appraisal of the physical environment score for parents/guardians and child/adolescents, in the waiting room and therapy rooms

\begin{tabular}{|c|c|c|c|c|}
\hline & \multicolumn{2}{|c|}{ PARENTS/GUARDIANS } & \multicolumn{2}{|c|}{ CHILD/ADOLESCENTS } \\
\hline & WAITING ROOM & THERAPY ROOMS & WAITING ROOM & THERAPY ROOMS \\
\hline Calm & $.43^{*}$ & $.41^{*}$ & $.48^{*}$ & $.53^{*}$ \\
\hline Bored & $-.40^{*}$ & $-.36^{*}$ & $-.49^{*}$ & $-.46^{*}$ \\
\hline Uncomfortable & $-.56^{*}$ & $-.47^{*}$ & $-.52^{*}$ & $-.38^{*}$ \\
\hline Afraid & $-.29^{*}$ & -.20 & -.02 & $-.17 *$ \\
\hline
\end{tabular}

$\mathrm{p}<.05$

.001). Therefore results suggest that clinicians reporting a more favourable appraisal of the physical environment also tended to report a higher level of overall work satisfaction.

\section{Discussion}

There is abundant research literature investigating the impact of the physical environment in office settings, $[7,22,23]$ however research investigating environmental influences in the context of mental health services is limited. [8] Therefore the present study sought to add to the research literature by examining clinicians and client perceptions of the quality of the physical environment in CAMHS. Of additional interest was, how these perceptions would relate to the emotional experience reported by clients and the work satisfaction reported by clinicians. Across all clinics, the mean overall rating by child/adolescents and parent/ guardians for both the waiting room and therapy rooms was 'good'. Clinicians were found to have a significantly lower appraisal of the physical environment with a mean overall appraisal of 'OK'. The precise reason for the discrepancy between clients and clinicians is beyond the scope of the present research. Perhaps the more positive appraisal of clients is related to the quality of service they receive. Or perhaps the more negative appraisal of clinicians is related to the fact that clinicians occupy the space to a greater extent, and this familiarity lends itself to noticing all the imperfections within the physical environment.

In the present study the emotional self-reported experience of clients within the clinic space was examined and results were encouraging as most parents/guardians and child/ adolescents reported being calm in both the waiting room and therapy rooms 'often'. Responses to negative emotions such as boredom, uncomfortableness and fear were typically reported as 'sometimes' or 'never'. Therefore results of the present study suggest that in the Western
Australian metropolitan CAMHS surveyed there was an overall positive appraisal of the physical environment and overall positive emotional experience reported by clients. An aim of the present study was to investigate if the client appraisal of the physical environment would be associated with their reported emotional experience. A moderatestrong positive association was found between the client perception of the physical environment and their overall emotional experience within the environment. Therefore results were consistent with expectations that the physical environment and emotional experience when in the clinic would be associated. This provides empirical evidence to support the intuitive notion that the physical environment can influence the experience of clients. In a mental health context the practical implication is that an improved physical environment is likely to improve the therapeutic process and therefore increase efficiency and efficacy of a clinic. Furthermore, these findings support the strategy taken by the National Youth Mental Health Foundation's Headspace initiative to be mindful in the design of the physical environment for mental health services. $[16,17]$

Another important finding of the present study was that many of the surveyed clinicians were relatively dissatisfied with the physical work environment, and that satisfaction with the physical work environment had a strong positive association with reported overall work satisfaction. The present study is therefore consistent with literature reporting an association between an appraisal of the physical environment with work satisfaction in a range of settings. [21,22] By their very nature, service industries are focused more upon maintaining a positive client experience rather than upon the service provider, however mental health services are arguably at the extreme end of the spectrum for focus upon client experience over service provider experience. A focus on the client is obviously of 
paramount importance for mental health services, however research literature suggests that working in the mental health industry puts additional strain upon staff compared to other industries due to constant exposure to individuals experiencing emotional/mental distress. [28] This places mental health workers at an elevated risk of burnout that can reduce productivity and morale that can consequently produce increased levels of staff turnover. [25,26] Results suggest that improving the quality of the physical environment has potential to not only foster positive client emotional experience, but also is likely to increase clinician work satisfaction in mental health services.

In order to improve the physical environment, service managers will constantly question where to allocate their limited resources. In the present study separate ratings for a number of indoor environmental attributes (comfort, safety, space, privacy, lighting and noise) and interior design attributes (toys/books, artwork and plants) were obtained from clinicians and clients. Results supported an interpretation that clinicians and clients have a holistic perception of the clinical environment, where all surveyed environmental attributes influence each other, and in turn the overall perception of the environment. For example, a nice piece of artwork might make a small space seem larger, or a noisy environment might detract from a sense of privacy, and so on. These results are consistent with research findings in other service environments reporting inter-relationships among the perception of different environmental attributes. [27] A practical recommendation from the findings of the present research is that service managers need not be resigned to accepting a bad spot within a facility. As an example, an area that might be considered a bit cramped could be enhanced via a number of different actions like soundproofing, investing in appropriate artwork/toys/plants, improving lighting, and more comfortable furnishings. Further research is required in order to tease apart the relative importance of different kinds of attributes (e.g., is investing in a plant more effective than a piece of artwork?). This type of enquiry would be best served by experimental approaches such as what has been previously conducted by Devlin and colleagues. [13-15]

A limitation of the present study was the correlational, rather than experimental, methodology. Expected relationships were found between appraisal of the physical environment and outcome measures such as emotional experience and work satisfaction. However the correlational nature of results leaves open the possibility that the outcome measures were also influencing appraisal of the physical environment. For example, a highly anxious client may come into the clinic feeling uncomfortable, and this may influence their perception of how comfortable the environment is. Alternatively, the open-ended responses provided by clients suggested that when completing the survey the clients might have been influenced by their positive experience of the service they were receiving. For example, a parent/guardian commented 'considering what you guys do to help... I can't complain. At the end of the day - if I get the same level of service I'm getting now - I'll be happy to sit on a milk crate - Thanks guys you all rock'. It might be that in a mental health context clients are more focused upon their own subjective experience, and their experience of receiving help, rather than critically appraising the physical environment. In another example a child/adolescent commented 'this place is great, everyone is nice and I rarely feel anxious here. Thanks.' This is consistent with research suggesting that receiving good service can influence the overall experience and perception of a service environment. [29] In future research, it would be useful to obtain first impressions regarding the physical environment and investigate if these impressions can predict future therapeutic alliances and outcomes. Another method of inquiry might be to experimentally vary the physical environment for therapy sessions to explore how the environment influences important therapeutic factors such as extent of self-disclosure and reported level of comfort. The possibility that client therapeutic experience may be influencing their perception of the physical environment does not however preclude the usefulness of present research findings. Instead, the implication is that future research needs to consider and control for pre-existing emotion in order to fully uncover the impact the physical environment is having upon the client. The present study produced findings that suggest a possible bi-directional relationship exists between emotional experience and physical surroundings that warrant further investigation.

\section{Competing interests}

The authors declare that they have no competing interests. 


\section{References}

1. Ackerman SJ, Hilsneroth MJ. A review of therapist characteristics and techniques positively impacting the therapeutic alliance. Clin Psychol Rev. 2003;23(1):1-33.

2. Pressly PK, Heesacker M. The physical environment and counseling: a review of theory and research. J Couns Dev. 2001;79:148-60.

3. Weeks W. Creating attractive services which citizens want to attend. Australian Social Work. 2004;57(4):319-30.

4. Miwa $Y$, Hanyu K. The effects of interior design on communication and impressions of a counselor in a counseling room. Environ Behav. 2006;38:484-502.

5. Aries MBC, Veitch JA, Newsham GR. Windows, view, and office characteristics predict physical and psychological discomfort. J Environ Psychol. 2010;30:533-41.

6. Devlin AS, Arneill AB. Health care environments and patient outcomes: a review of the literature. Environ Behav. 2003;35:665-94.

7. Rashid M, Zimring C. A review of the empirical literature on the relationships between indoor environment and stress in health care and office settings: problems and prospects of sharing evidence. Environ Behav. 2008;20(2):151-90.

8. Connellan K, Gaardboe M, Riggs D, Due C, Reinschmidt A, Mustillo L. Stressed spaces: mental health and architecture. Health Environments Research and Design Journal. 2013;6(4):127-268.

9. Ornstein S. First impressions of the symbolic meanings connoted by reception area design. Environ Behav. 1992;24:85-110.

10. Arneill $A B$, Devlin AS. Perceived quality of care: the influence of the waiting room environment. J Environ Psychol. 2002;22:345-60.

11. Greenburg RP. Effects of impresession information on perception of the therapist and receptivity to influence in a psychotherapy analogue. J Consult Clin Psychol. 1969;33(4):425-9.

12. Claiborn CD, Schmidt LD. Effects of impresession information on the perception of the counselor in an interview. J Couns Psychol. 1977;24(4):259-63.

13. Nasar JL, Devlin AS. Impressions of psychotherapists' offices. J Couns Psychol. 2011;58(3):310-20.

14. Devlin AS, Nasar JL, Cubukcu E. Students' impressions of psychotherapists' offices: cross-cultural comparisons. Environ Behav. 2013:1-26.

15. Devlin AS, Nasar JL. Impressions of psuchotherapists' offices: do therapists and clients agree? Prof Psychol Res Pr. 2012;43:118-22.

16. McGorry PD, Bates T, Birchwood M. Designing youth mental health services for the 21st century: examples from Australia, Ireland and the UK. Br J Psychol. 2013;202:s30-s5.

17. Rickwood DJ, Telford NR, Parker AG, Tanti CJ, McGorry PD. headspace - Australia's innovation in youth menthal health: who are the clients and why are they presenting? Med J Aust. 2014;200:1-4.

18. Jorm AF. How effective are 'headspace' youth mental health services. Aust N Z J Psychiatry. 2015;49(10):861-2.

19. Simmons M, Parker AG, Hetrick SE, Telford NR, Bailey A, Rickwood DJ. Development of a satisfaction scale for young people attending youth mental health services. Early Interv Psychiatry. 2014; 8(4):382-6

20. Rickwood DJ, Nicholas A, Mazzer K, Telford NR, Parker AG, Tanti CJ, ,et al. Satisfaction with youth mental health services: further scale development and findings from headspace - Australia's National Youth Mental Healh Foundation. Early Interv Psychiatry. 2015.

21. Veitch JA, Charles KE, Farley KMJ, Newsham GR. A model of satisfaction with open-plan office conditions: COPE field findings. J Environ Psychology. 2007;27:177-89.
22. Davis MC, Leach DJ, Clegg CW. Chapter 6: The physical environment of the office: Contemporary and emerging issues. International Review of Industrial and Organizational Psychology. 2011; 26:193-237.

23. Thayer JF, Verkuil B, Brosschotj JF, Kevin K, West A, Sterling C, et al. Effects of the physical work environment on physiological measures of stress. Eu J Cardiovasc Prev Rehabil. 2010;17:431-9.

24. Folkins C, O-Reilly III C, Roberts K, Miller S. Physical environment and job satisfaction in a community mental health center. Community Ment Health J. 1977;13(1):24-30.

25. Littlewood S, Case P, Gater R, Lindsey C. Recruitment, retention, satisfaction and stress in child and adolescent psychiatrists. Psychiatr Bull. 2003;27:61-7.

26. Aarons GA, Sawitzky AC. Organisational climate partially mediates the effect of culture on work attitudes and staff turnover in mental health services. Administration and Policy in Mental Health Services Research. 2006;33(3):289-301.

27. Spielmann N, Laroche M, Borges A. How service seasons the experience: Measuring hospitality servicescapes. International Journal of Hospitality Management. 2012;31(2):360-8.

28. Hannigan B, Edwards D, Burnard P. Stress and stress management in clinical psychology: findings from a systematic review. J Ment Health. 2004;13(3):235-45.

29. Weinstein N, Legate N, Przybylski AK. Beauty is in the eye of the psychologically fulfilled: how need satisfying experiences shape aesthetic perceptions of spaces. Motiv Emot. 2013;37(2):245-60. 